\title{
Attitudes of consumers and healthcare professionals towards the patient package inserts - a study in Palestine
}

\author{
Rowa' AL-RAMAHI, Abdel N. ZAID, Na'em KETTANA, Waleed SWEILEH, Doa' AL-JABI.
} Received (first version): $20-$ Sep-2011

Accepted: 22-Feb-2012

\begin{abstract}
${ }^{*}$
Reading the patient package inserts (PPIs) is a key source of information about medications for patients. They should be clear and understandable to the general population.

Objectives: The aims of this study were to obtain base-line data on the extent of reading PPIs by consumers and possible factors that might affect this; to explore the attitude of the Palestinian public and healthcare professionals towards the patient package inserts (PPIs); and to review a random sample of PPIs for the availability of different information.

Methods: The first part of the study was a crosssectional self-administered questionnaire. The questionnaire for consumers included 15 items. The questionnaire for healthcare professionals included 10 items and it was very similar to that of consumers with some modifications. In the second part, a random sample of PPIs was reviewed. In our community pharmacies, where medications are arranged according to their producing company, a researcher was asked to choose randomly 10-15 medications for every company to check for the availability of pharmacological, pharmaceutical and clinical information.
\end{abstract}

Results: A total of 304 healthcare professionals out of $320(95.0 \%)$ and 223 consumers out of 240 $(92.9 \%)$ accepted to answer the survey. Forty five percent consumers reported that they always read the PPIs, and $29.3 \%$ said that they read the PPIs most of the times. Increased rate of reading the leaflet was found among females $(P=0.047)$. The preferred language for the PPIs was Arabic for most of the consumers (89.6\%) while it was English for most of the healthcare professionals $(80.8 \%)$. $35.9 \%$ of the consumers and $43.6 \%$ of the healthcare professionals found the font size suitable. $42.3 \%$ of the consumers and $25.5 \%$ of the healthcare professionals said that they found the

Rowa AL-RAMAHI. Assistant Professor of Clinical Pharmacy. Department of Pharmacy, AnNajah National University. Nablus (Palestine).

Abdel N. ZAID. Associate Professor of Pharmaceutical Chemistry and Technology. Department of Pharmacy, AnNajah National University. Nablus (Palestine). Na'em KETTANA. Instructor of Pharmacology.

Department of Pharmacy, AnNajah National University. Nablus (Palestine).

Waleed SWEILEH. Professor of Clinical Pharmacology. Department of Pharmacy, AnNajah National University. Nablus (Palestine).

Doa' AL-JABI. MSc program in Clinical Pharmacy. Department of Pharmacy, AnNajah National University. Nablus (Palestine) information in the PPIs useful and enough. The PPIs of 135 randomly sampled medications were reviewed. Many important sections were not found in the PPIs' sample.

Conclusion: A high percentage of consumers read the PPIs, but still this needs to be improved. People would appreciate a more detailed and clear PPI. Pharmacists should advocate reading the PPIs but they need to provide consumers with detailed counseling to compensate for the missing information in some of the PPIs. Authorities and manufacturers should implement appropriate measures to regulate the quality and quantity of information in the PPIs.

Keywords: Drug Labeling. Comprehension. Information Dissemination. Middle East.

\section{ACTITUDES DE CONSUMIDORES Y PROFESIONALES DE LA SALUD HACIA LOS PROSPECTOS- ESTUDIO EN PALESTINA}

\section{RESUMEN}

Leer el prospecto del medicamento es una fuente clave de información sobre medicamentos para los pacientes. Los prospectos deberían ser claros y comprensibles para una población general. Objetivos: Los objetivos de este estudio fueron obtener un punto de partida para aumentar la lectura delos prospectos por los consumidores, y los posibles factores que pueden afectar a esto; explorar la actitud del público y profesionales de la salud palestinos hacia los prospectos de medicamentos; y revisar una muestra aleatoria de prospectos para ver la disponibilidad de diferentes informaciones.

Métodos: La primera parte del estudio fue un cuestionario transversal auto-administrado. El cuestionario incluía 15 ítems. El cuestionario para profesionales de la salud incluía 10 ítems y era similar al de los consumidores con algunas modificaciones. En la segunda parte, se revisó una muestra aleatoria de prospectos. En nuestras farmacias comunitarias, donde los medicamentos se organizan por compañía productora, se pidió a un investigador que eligiese aleatoriamente 10-15 medicamentos de cada compañía para investigar la disponibilidad de información farmacológica, farmacéutica y clínica.

Resultados: Un total e 304 de los 320 (95,0\%) profesionales de la salud y 223 de los $240(92,9 \%)$ consumidores aceptó responder el cuestionario. Un $45 \%$ de los consumidores comunicó leer siempre 
los prospectos, y un $29,3 \%$ dijo leer los prospectos la mayoría de las veces. Se encontró una tasa mayor de lectura en las mujeres (p?0,047). El idioma preferido para los prospectos fue el árabe para la mayoría de los consumidores $(89,6 \%)$ mientras que el inglés lo fue para la mayoría de los profesionales de la salud $(80,8 \%)$. El 35,9\% de los consumidores y el $43,6 \%$ de los profesionales encontraron el tamaño de letra adecuado. El 42,3\% de los consumidores y el $25,5 \%$ de los profesionales dijo que la información de los prospectos era útil y suficiente. Se revisaron los prospectos de 135 medicamentos aleatoriamente seleccionados. No se encontraron muchas secciones importantes en la muestra de prospectos.

Conclusión: Un elevado porcentaje de consumidores lee los prospectos de medicamentos, pero esto aún debe ser mejorado. La gente preferiría un prospecto más claro y detallado. Los farmacéuticos deberían promover la lectura de los prospectos pero necesitan proporcionar a los pacientes consejo detallado para compensar las carencias de información de algunos prospectos. Las autoridades y la industria deberían implantar medidas apropiadas para regular la calidad y la cantidad de información de los prospectos.

Palabras clave: Etiquetado de Medicamentos. Comprensión. Diseminación de Información. Medio Oriente.

\section{INTRODUCTION}

The patient package inserts (PPIs) are included by law in the packaging of drugs and contain information for the user. They are the most readily available form of written information on drugs for patients. The leaflet is meant to be clear and understandable to the general population. The PPIs should increase patient's awareness of medicationrelated issues, contribute to the safe and correct use of the medication, and help in the success of the treatment plan. ${ }^{1,2}$ In developing countries, the PPI is considered an important source of drug information for healthcare providers as well, because of a limited ability to access up to date drug information resources. Even though it is an important source of information, several studies from different countries have shown a need to improve the content and readability of the PPI. ${ }^{1-8}$ Despite efforts to improve the readability and comprehensibility, by both the drug regulatory authorities and the manufactures, package inserts are still criticized. ${ }^{1,3-5}$ This is mainly due to the extensive volume of incomprehensible text and the small font size used, which people find distressing. ${ }^{5,9}$

Risks for medication misuse highlight the importance of reviewing package inserts and labels prior to taking medications. Reading package labels is a key source of information about medications for many consumers especially in developing countries where self-medication is well documented and access to clinicians and pharmacists might be limited, so incomplete or inaccurate information in
PPIs might increase medication errors and drugrelated problems. ${ }^{10}$ Globally there is considerable variation in the information included in the package inserts or leaflets, as well as the primary users they are directed toward. The design and the amount of information in the PPIs are usually regulated by the legislative health authorities. The medications in community pharmacies in Palestine are almost exclusively available by branded unit-of-use, with a product insert inside every package. This informative insert is directed toward the users and must give full and comprehensible information about the drug. The Palestinian Ministry of Health (MoH) recommends that all marketed medications be supplied with a PPI that is written in both Arabic and English, but there are no regulations regarding the quality or the quantity of the information, design and wording of the PPI. ${ }^{11,12}$ The aims of this study were to obtain base-line data on the extent of reading PPIs by consumers and possible factors that might affect this, to explore the attitude of the Palestinian public and healthcare professionals towards the patient package inserts, and to review a random sample of PPIs for the availability of different information. Results of this study provide information for healthcare providers and educators. Improvements in self-education about medications may be related to appropriate use of medications and improve people's ability to care for medical problems.

\section{METHODS}

The first part of the study was a cross-sectional selfadministered questionnaire. It was conducted between March and May 2010. The questionnaires were developed based on review of literature and intended to assess the general attitude of patients and healthcare professionals (physicians and pharmacists) towards PPIs, their comprehensibility, and the information that they need to find in the PPIs. The questionnaire for consumers included 15 items: the first part included information regarding patient demographics and clinical characteristics including: sex, age, education, place of living, insurance, evaluation of health status in general, and presence of chronic diseases. The consumers were asked if they read the PPI and check the expiry date before using medication, if they find the font size suitable, what is the language that they prefer to read the PPIs in, if they find the information in the PPIs clear and enough, if they think that the PPIs in our country need improvement and if they think that a free number in the PPIs to give any required drug information can be useful. Finally, they were given a list of PPIs sections and were asked what parts they find important and useful to them. The questionnaire for healthcare professionals included 10 items and it was very similar to that of consumers with some modifications. Professionals were asked about their sex, age, specialty and years of experience. They were asked if they find the font size suitable, what is the language that they prefer to read the PPIs in, if they find the information in the PPIs clear and enough, if they think that the PPIs in our country need improvement and if they think that a free 


\begin{tabular}{|c|c|c|c|c|}
\hline \multirow[t]{2}{*}{ Section Importance } & \multicolumn{2}{|c|}{$\begin{array}{l}\text { Consumers N (\%) } \\
\quad \mathrm{N}=223\end{array}$} & \multicolumn{2}{|c|}{$\begin{array}{l}\text { Healthcare Professionals } \mathrm{N}(\%) \\
\qquad \mathrm{N}=304\end{array}$} \\
\hline & Yes & No & Yes & No \\
\hline Active ingredient & $150(67.3)$ & $73(32.7)$ & $279(92.4)$ & $23(7.6)$ \\
\hline Clinical indication & $220(98.7)$ & $3(1.3)$ & $223(73.4)$ & $81(26.6)$ \\
\hline Contraindication & $211(94.6)$ & $12(5.4)$ & $295(97.0)$ & $9(3.0)$ \\
\hline Pregnancy implications & $184(83.3)$ & $37(16.7)$ & $300(98.7)$ & $4(1.3)$ \\
\hline Lactation implications & $182(82.0)$ & $40(18)$ & $300(98.7)$ & $4(1.3)$ \\
\hline Warnings and precautions & $221(99.1)$ & $2(0.9)$ & $298(98.0)$ & $6(2.0)$ \\
\hline Drug-Drug interaction & $201(90.5)$ & $21(9.5)$ & $292(96.4)$ & $11(3.6)$ \\
\hline Drug-food interactions & $198(88.8)$ & $25(11.2)$ & $285(94.1)$ & $18(5.9)$ \\
\hline Adverse drug reactions & $217(97.3)$ & $6(2.7)$ & $293(96.4)$ & $11(3.6)$ \\
\hline Dosages & $196(87.9)$ & $27(12.1)$ & $277(91.4)$ & $26(8.6)$ \\
\hline Direction for use & 207 (93.2) & $15(6.8)$ & $290(95.4)$ & $14(4.6)$ \\
\hline Overdose toxicity & $203(91.0)$ & $20(9.0)$ & $285(93.8)$ & $19(6.2)$ \\
\hline Storage condition & $180(80.7)$ & $43(19.3)$ & $275(90.8)$ & $28(9.2)$ \\
\hline Expiry after opening or reconstitution & $218(97.8)$ & $5(2.2)$ & $296(97.4)$ & $8(2.6)$ \\
\hline List of excipients (inactive ingredients) & $40(19.0)$ & $171(81.0)$ & $100(32.9)$ & $204(67.1)$ \\
\hline $\begin{array}{l}\text { Storage conditions after opening or reconstitution of } \\
\text { the drug }\end{array}$ & $194(92.8)$ & $15(7.2)$ & $291(95.7)$ & $13(4.3)$ \\
\hline Possibility of tablet splitting & $173(82.0)$ & $38(18.0)$ & $246(81.2)$ & $57(18.8)$ \\
\hline $\begin{array}{l}\text { Possibility of crushing tablets or opening capsules to } \\
\text { mix with food or beverages }\end{array}$ & $167(79.1)$ & $44(20.9)$ & $249(82.2)$ & $54(17.8)$ \\
\hline $\begin{array}{l}\text { Instructions to convert tablets or capsules into liquid } \\
\text { dosage forms when they are not available }\end{array}$ & $158(74.9)$ & $53(25.1)$ & $232(76.3)$ & $72(23.7)$ \\
\hline Pharmacokinetics information & NA & NA & $134(44.2)$ & $169(55.8)$ \\
\hline
\end{tabular}

number in the PPIs to give any required drug information can be useful. They were given a list of PPIs sections and were asked what parts they find important and useful to them. The professionals' list included pharmacokinetics data, consumers were not asked about this section because it might be difficult for them to understand this. The questionnaires were in Arabic, the last question that included sections of the PPIs was in both Arabic and English. Preliminary test of the questionnaires was conducted on 20 persons for each and slightly modified according to this. After having the approval from the Institutional Review Board at An-Najah National University, the questionnaires were distributed randomly by 30 fourth year pharmacy students. They were asked to choose consumers and healthcare professionals from their living areas. The students are from various cities and villages in the West Bank, so a convenient sample from randomly selected places was obtained. In the second part of the study, a random sample of 135 PPIs was reviewed. In our community pharmacies, the medications are arranged according to their producing company, a researcher was asked to choose randomly 10-15 medications for every company to check for the availability of pharmacological, pharmaceutical and clinical information as active ingredient, adverse drug reactions, warnings and precautions, clinical indication, contraindication, drug-drug interaction, direction for use, storage condition, overdose toxicity, dosages, pregnancy implications, lactation implications, list of excipients (inactive ingredients), and expiry after opening or reconstitution. The data were entered and descriptively analyzed using the Statistical Package for the Social Sciences (SPSS) software program version 16.0. Associations between categorical variables and reading PPIs were assessed using the chi-square test.

\section{RESULTS}

A total of 304 healthcare professionals and 223 consumers answered the survey. The healthcare professionals were 146 physicians and 158 pharmacists. Only 16 physicians and pharmacists refused to fill the questionnaire giving a response rate of $95 \%$. Out of 240 consumers, 223 accepted to participate giving a response rate of $92.9 \%$. The consumers' sample consisted of $37.6 \%$ males and $62.4 \%$ females. The distribution of their ages was: $16-26$ (28.1\%), 26-39 (21.9\%), 40-59 (44.8\%), and 60 or older $(4.0 \%)$

Among the 222 consumers who answered the question regarding the reading of the PPIs, 100 patients $(45.0 \%)$ reported that they always read the information in the leaflet of the drug package, 65 $(29.3 \%)$ said that they read the PPIs most of the times, $41(18.5 \%)$ said that read it sometimes, and only $16(7.2 \%)$ participants said that they rarely or do not read the PPIs.

Consumers' age, education, place of living, health status in general, and presence of chronic diseases were not associated with reading the PPIs, but gender was. Increased rate of reading the PPIs was found among females $(P=0.047)$. Of the 223 consumers who answered the questionnaire, 183 $(82.1 \%)$ said that they read the expiry date of the medications before using them, $10(4.5 \%)$ said that they do not read it and $30(13.5 \%)$ said that they read the expiry date sometimes.

The consumers and the healthcare professionals were asked if they find the font size in the PPIs suitable for reading or not? $35.9 \%$ of the consumers and $43.6 \%$ of the healthcare professionals answered with yes, $28.7 \%$ of the consumers and $18.5 \%$ of the healthcare professionals answered 


\begin{tabular}{|l|c|}
\hline Table 2. The availability of information in a sample of patient package inserts \\
\hline Information & $\begin{array}{c}\text { Total N (\%) } \\
\mathrm{N}=135\end{array}$ \\
\hline Active ingredient & $135(100.0)$ \\
\hline Adverse drug reactions & $134(99.3)$ \\
\hline Warnings and precautions & $133(98.5)$ \\
\hline Clinical indication & $131(97.0)$ \\
\hline Contraindication & $129(95.6)$ \\
\hline Drug-Drug interaction & $127(94.1)$ \\
\hline Direction for use & $126(93.3)$ \\
\hline Storage condition & $117(86.7)$ \\
\hline Overdosage toxicity & $96(71.1)$ \\
\hline Dosages & $94(69.6)$ \\
\hline Pregnancy implications & $92(68.2)$ \\
\hline Lactation implications & $86(63.7)$ \\
\hline List of excipients (inactive ingredients) & $65(48.2)$ \\
\hline Expiry after opening or reconstitution & $64(47.4)$ \\
\hline Pharmacokinetics information & $11(8.2)$ \\
\hline Drug-food interactions & $27 / 106(25.5)$ \\
\hline Storage conditions after opening or reconstitution of the drug & $16 / 47(34.0)$ \\
\hline Possibility of tablet splitting & $16 / 47(34.0)$ \\
\hline Possibility of crushing and mixing with food or beverages & $8 / 47(17.0)$ \\
\hline Instructions to convert tablets or capsules into liquid forms & $0 / 47(0.0)$ \\
\hline
\end{tabular}

with no, and third group of $35.4 \%$ consumers and $38.0 \%$ healthcare professionals said that they find font size suitable sometimes and very small other times.

The preferred language for the PPIs was Arabic for most of the consumers (89.6\%) while it was English for most of the healthcare professionals $(80.8 \%)$. Among the consumers who read the PPIs, 94 $(42.3 \%)$ said that they found the information in the PPIs useful and enough, while $32(14.4 \%)$ found the PPIs to be vague, un-useful and that they could not find the needed information readily. A third group, $96(43.2 \%)$ said that they sometimes find the PPIs useful and enough, and sometimes not. Less healthcare professionals $77(25.5 \%)$ found the information in the PPIs enough, 111 (36.8\%) of them thought it was not enough, and 114 (37.7\%) said it is sometimes enough.

The attitudes of consumers and healthcare professionals towards the importance of different information sections of the patient package inserts are shown in Table 1. They both told that they find most sections of the PPIs important and useful to them.

When the participants were asked if they think that the information in the PPIs need to be improved, $167(74.0 \%)$ of the consumers and $252(83.7 \%)$ of the healthcare professionals answered with yes. $212(95.1 \%)$ the consumers and $255(84.7 \%)$ of the healthcare professionals thought that a free telephone number in the PPIs would be a good idea to provide drug information when needed.

The PPIs of 135 medications were reviewed for the availability of pharmacological and pharmaceutical information. Some sections were available in most of the PPIs reviewed (>90\%). Those sections were: active ingredient, adverse drug reactions, warnings and precautions, clinical indication, contraindication, drug-drug interaction, and direction for use. Other sections as storage condition, overdose toxicity, dosages, pregnancy implications, lactation implications, list of excipients (inactive ingredients), and expiry after opening or reconstitution were available in some PPls with rates ranging from $86.7 \%$ to $47.4 \%$. For the rest of the sections, they were not included in most of the PPIs (Table 2).

\section{DISCUSSION}

The PPI has to reinforce or even supplement professional explanations. Written information which is available to the patient at home can help to bridge the communication gap between patient and physician reinforcing the warnings, instructions and explanations given to the patient by both doctor and pharmacist. Rates of reading the package insert vary. In our study, $45.0 \%$ reported that they always read the information in the PPIs, $29.3 \%$ said that they read them most of the times. Compared to other countries, a study from the United States has shown that for leaflets provided with new medications, $49.2 \%, 21.2 \%, 16.0 \%$, and $13.7 \%$ of surveyed patients reported reading the leaflets always, often, seldom, or never, respectively. ${ }^{13}$ In Turkey, $78.2 \%$ patients reported that they read the leaflets. ${ }^{14}$ A survey performed in Italy showed that most of the patients $(83.4 \%)$ read the PPIs. ${ }^{3}$ Horwitz et $a l,{ }^{15}$ found that $79 \%$ always or often read the patient information leaflets. In a survey from the United Kingdom, 47\% patients said that they read some of the patient information leaflet, and. $35 \%$ said that the read it all. ${ }^{16}$ These results show that a high percentage of our consumers read the PPIs before using the medications, but still the importance of this needs to be confirmed. Health professionals, particularly pharmacists, are well placed to raise awareness of this. Pharmacists should advocate reading the leaflet and promote it as a useful resource of drug information. In this study, it was found that the gender was the only demographic variable associated with reading the leaflet. Koo et al, ${ }^{17}$ investigated patients' use of written medicine information in Australia, they have found that the level of patient health literacy, health locus of control, occupation, patient coping style and the nature of the health problem were all associated with patient interest in written materials. Another study has shown that literacy was positively 
associated with reading of written medicine information, while age was negatively associated with reading them. ${ }^{18}$

In this study, $28.7 \%$ of the consumers and $18.5 \%$ of the healthcare professionals said that they do not find the font size in the PPIs suitable for reading, and $35.4 \%$ consumers and $38.0 \%$ healthcare professionals said that they find font size suitable sometimes and very small other times. In a study by Bernardini et al, ${ }^{4}$ a great majority of the respondents $(63.1 \%)$ said that the print size is too small. This percentage rose with increasing age. From their survey it emerged that people would prefer 10 and 11 points. In Horwitz et al. ${ }^{15}$ study, $38 \%$ of the interviewed patients had problems reading or understanding the patient information leaflets. Older consumers may be unable to acquire information in the 'fine' print frequently found in various kinds of product inserts. ${ }^{19}$ It is recommended that a suitable size should be chosen. PPI inserted in medicines for geriatric pathologies should be written in at least 10 points Didot. Recently, the Pharmaceutical Committee of the European Commission has also taken into consideration the formal aspects of the PPIs and has formulated a guideline on the readability of the label and PPIs of medicinal products for human use. ${ }^{4}$ According to such a guideline, the information appearing in the leaflet should be printed in characters of at least 8 points Didot and one or several colors may be used for printing characters because the use of different colors is one way of making headings clearly recognizable. Capitals letters should not be used indiscriminately because they detract from the readability, but they may be useful for emphasis. As we do not have our own guidelines, our $\mathrm{MoH}$ could benefit from these guidelines to improve the readability of the PPIs in our market.

Among the consumers who read the PPIs, $42.3 \%$ said that they found the information in the PPIs useful and enough and less healthcare professionals $25.5 \%$ found the information in the PPIs enough. Inadequate information in the PPIs has been reported by authors in different countries. In a study carried out in Saudi Arabia, the authors found that there was substantial disagreement in information between generic package inserts and the British National Formulary and the package inserts of the brand products marketed in Saudi Arabia. ${ }^{6}$ In the USA, it was shown that PPIs do not fully meet the federal regulations. ${ }^{20} \mathrm{~A}$ European study found substantial disagreement in the materials available to prescribers and patients in different countries. ${ }^{21} \mathrm{~A}$ study in our country found that there is a significant difference in the quantity and quality of information provided in the PPIs of locally and imported anti-infective agents. ${ }^{12}$ Another study has found that instructions for storage and proper use were not available in package inserts of many oral drops products in Palestine. ${ }^{22}$ PPIs improvement will better direct health practices to the benefit of the patients. In Bernardini et al. ${ }^{4}$ study, the great majority of respondents $(60.6 \%)$ preferred a more detailed leaflet. Regarding the subgroups, the percentage increased with decreasing levels of study. Most of the population (61.1\%) said that they would prefer a more schematic and concise leaflet. It is apparent that our patients and healthcare professionals would appreciate a more detailed PPI, but information should be given in schematic and concise way. This requires the $\mathrm{MoH}$ to develop clear regulations regarding the content of the PPIs.

Consumers and healthcare professionals find most sections of the PPIs important and useful. Despite the importance of these sections, a review of a sample of PPIs has shown that many PPIs in our market miss some sections or include unclear and unspecific information. A study from USA to evaluate the distribution and quality of patient medication leaflets provided in U.S. pharmacies has found that fewer than $10 \%$ of all leaflets met quality criteria regarding contraindications, precautions, and how to avoid harm. One fourth of all leaflets had poor print size, according to the shoppers. ${ }^{20}$ Another study to evaluate the quality of patient information leaflets provided with dispensed medications in the United States, United Kingdom, and Australia has found that the U.S. leaflets achieved $\leq 50 \%$ adherence for contraindication and precaution information. Omissions included warnings about preexisting allergy and illness and information about drug interactions. The U.S. leaflets also scored poorly $(60 \%)$ for legibility and comprehensibility. The U.K. score reflected shortcomings in information about how to use and monitor the medications and on adverse drug reactions. $^{8}$ In Germany, a study of 68 German package inserts for a detailed analysis of their quality and suitability has found that in many cases package inserts did not include important information or were difficult to read or understand. ${ }^{23}$ It seems that this problem is seen in both developed and developing countries, as it was recommended before suitable regulations from our $\mathrm{MoH}$ can control this problem.

In general, $74.0 \%$ of the consumers and $83.7 \%$ of the healthcare professionals said that the information in the PPIs needs to be improved. It is clear that actions should be done to improve the pharmacological and the pharmaceutical contents in our PPIs. This requires regulations from related authorities and cooperation from pharmaceutical companies. There is definitely a need to update the guidelines for package inserts in line with those from the Western countries. Improvements such as adoption of a uniform format and implementation of guidelines regarding inclusion of relevant information could greatly enhance the quality and clarity, and satisfy the people needs.

A suggested solution that could be helpful if the PPIs cannot be modified to include all the required information is to include a free telephone number in the PPIs to provide extra drug information when needed. This idea was welcomed by $95.1 \%$ the consumers and $84.7 \%$ of the healthcare professionals. At our institution, we have a poison control and drug information center that provides drug related information freely. The free telephone number of this center can be added to the PPIs.

Our results should, however, be considered in the context of some limitations. Samples of consumers, 
healthcare professionals and medications for reviewing PPIs were collected randomly to have convenient samples. As they were collected by many pharmacy students, this raises the possibility of selection bias and might not be generalized to the general population. However, these results can give base-line data about the situation in our country which meets with the aims of this study. Also no measures were put in place to ascertain the claim made by participants about reading the PPIs, we just recorded what they said, further studies could assess this point.

\section{CONCLUSIONS}

A high percentage of the consumers read the PP before using the medications, but still the importance of this needs to be confirmed by pharmacists. Palestinian authorities and manufacturers should implement appropriate measures to regulate the quality and quantity of information in the patient package insert. PPIs improvement will better direct health practices to the benefit of the patients. Package inserts readability and content must be optimized. This will avoid misunderstandings and lack of information and ensure that use of the drug will give the best possible outcome and avoid safety risks. It is recommended that pharmacists should advocate reading the PPI and promote it as a useful resource of drug information, but they need to provide consumers with detailed counseling to compensate for the missing information in some of the PPIs. a suitable font size should be used in the PPIs to encourage people to read it easily, PPIs should be more detailed but the information should be given in a schematic and concise way, and PPIs should contain pharmaceutical information about the appropriate use of dosage forms.

\section{ACKNOWLEDGEMENTS}

We would like to extend our thanks and appreciation to all consumers, physicians and pharmacists who cooperated in filling the questionnaires and also to pharmacy students whose efforts in distributing and gathering them cannot be denied.

\section{CONFLICT OF INTEREST}

None.

Source of funding: none.

\section{References}

1. Didonet J, Mengue SS. Drug labels: are they a readable material? Patient Educ Couns. 2008;73(1):141-145.

2. Watson KT, Barash PG. The new Food and Drug Administration drug package insert: implications for patient safety and clinical care. Anesth Analg. 2009;108(1):211-218.

3. Bernardini C, Ambrogi V, Perioli L, Tiralti MC, Fardella G. Comprehensibility of the package leaflets of all medicinal products for human use: a questionnaire survey about the use of symbols and pictograms. Pharmacol Res. 2000;41(6):679-688.

4. Bernardini C, Ambrogi V, Fardella G, Perioli L, Grandolini G. How to improve the readability of the patient package leaflet: a survey on the use of colour, print size and layout. Pharmacol Res. 2001;43(5):437-444.

5. Fuchs J, Hippius M. Inappropriate dosage instructions in package inserts. Patient Educ Couns. 2007;67(1-2):157-168.

6. Gebran N, Al Haidari K. Assessment of prescribing information for generic drugs manufactured in the Middle East and marketed in Saudi Arabia. Ann Saudi Med. 2006;26(3):192-199.

7. Shivkar YM. Clinical information in drug package inserts in India. J Postgrad Med. 2009;55(2):104-107.

8. Raynor DK, Svarstad B, Knapp P, Aslani P, Rogers MB, Koo M, Krass I, Silcock J. Consumer medication information in the United States, Europe, and Australia: a comparative evaluation. J Am Pharm Assoc (2003). 2007;47(6):717-724.

9. Sansgiry S S, Cady PS, Patil S. Readability of over-the-counter medication labels. J Am Pharm Assoc (Wash). 1997;NS37(5):522-528.

10. Nabors LA, Lehmkuhl HD, Parkins IS, Drury AM. Reading about over-the-counter medications. Issues Compr Pediatr Nurs. 2004;27(4):297-305.

11. Sweileh WM, Zeid AN, Jaradat NA. Drug informational value of patient package insert (PPI): A sample study in Palestine. Journal of The Islamic University of Gaza, (Natural Sciences Series). 2004;12:59-68.

12. Sawalha AF, Sweileh WM, Zyoud SH, Jabi SW. Comparative analysis of patient package inserts of local and imported anti-infective agents in Palestine. Libyan J Med. 2008;3(4):181-185.

13. Nathan JP, Zerilli T, Cicero LA, Rosenberg JM. Patients' use and perception of medication information leaflets. Ann Pharmacother. 2007;41(5):777-782.

14. Savas S, Evcik D. Do undereducated patients read and understand written education materials? A pilot study in Isparta, Turkey. Scand J Rheumatol. 2001;30(2):99-102.

15. Horwitz A, Reuther L, Andersen SE. Patient information leaflets seen through the eyes of patients in a general practice. Ugeskr Laeger. 2009;171(8):599-602.

16. Raynor DK, Knapp P, Moody A, Young R. Patient information leaflets-impact of European regulations on safe and effective use of medicines. Pharm J. 2005;(275):609-611.

17. Koo M, Krass I, Aslani P. Enhancing patient education about medicines: factors influencing reading and seeking of written medicine information. Health Expect. 2006;9(2):174-187.

18. Miller MJ, Schmitt MR, Allison JJ, Cobaugh D J, Ray MN, Saag KG. The role of health literacy and written medicine information in nonsteroidal antiinflammatory drug risk awareness. Ann Pharmacother. 2010;44(2):274-284. 
19. Wogalter MS, Vigilante WJ Jr. Effects of label format on knowledge acquisition and perceived readability by younger and older adults. Ergonomics. 2003;46(4):327-344.

20. Svarstad BL, Mount JK, Tabak ER. Expert and consumer evaluation of patient medication leaflets provided in U.S. pharmacies. J Am Pharm Assoc. 2005;45(4):443-451.

21. Jambert E, Kopp C, Montane E, Rago L, Rocchi F. Prescribing information in 26 countries. A comparative study. Eur J Clin Pharmacol. 2003;59(4):263-270.

22. Zaid AN, Al-Ramahi R, Abu Ghoush A. Appropriate use of oral drops: perception of health professionals and assessment of package insert information. Int J Clin Pharmacol Ther. 2010;48(12):854-859.

23. Fuchs J, Hippius M, Schaefer M. Analysis of German package inserts. Int J Clin Pharmacol Ther. 2006;44(1):8-13. 